\title{
SCIENTIFIC REP RTS \\ Degree of severity of molar incisor hypomineralization and its relation to dental caries
}

Received: 4 October 2017

Accepted: 9 January 2018

Published online: 19 January 2018

\section{A. Negre-Barber, J. M. Montiel-Company, M. Catalá-Pizarro \& J. M. Almerich-Silla}

Molar incisor hypomineralization is a developmental defect of dental enamel associated with rapid caries progression. In order to discover whether molar incisor hypomineralization predisposes to dental caries, a cross-sectional cohort study was conducted in a sample of 414 children aged between eight and nine years. It was found that $24.2 \%$ of the children presented molar incisor hypomineralization. Of these, $72 \%$ had a mild form and $28 \%$ a severe form. Caries prevalence was greater among the children with severe form (60.7\%) than in those with mild form (43.1\%) or no molar incisor hypomineralization (45.5\%). The caries indices were higher in out molar incisor hypomineralization (1.18) or with mild form (1.08). The tooth-surface caries ratio was significantly higher in surfaces with severe hypomineralization than in those with no hypomineralization or mild hypomineralization. A linear regression model showed that cariogenic food intake and the presence of severe molar incisor hypomineralization were significantly associated with DMFS. Consequently, an association was found to exist between dental caries and the presence of surfaces affected by severe molar incisor hypomineralization, which should be considered a risk factor within the multifactorial etiology of caries.

Dental caries and developmental defects of enamel (DDE) are currently the most frequent problems observed in primary dentition and early permanent dentition. DDE are due to faulty enamel formation, which makes the enamel more susceptible to attack by acids and, therefore, to dental caries. The defective enamel provides an ideal environment for plaque adhesion and colonization by cariogenic bacteria, enabling lesions to progress rapidly ${ }^{1,2}$. DDE include molar incisor hypomineralization $(\mathrm{MIH})^{3}$, which has prevalence rates ranging between $2.9 \%$ and $44 \%$ in different countries ${ }^{4}$.

Molar incisor hypomineralization (MIH) is a mineralization disorder that affects the permanent first molars and, on occasion, the permanent incisors. It can present in a mild form consisting of opacities with a white/ yellow/brown tone of color, or a severe form with post-eruptive enamel breakdown (PEB), caries, atypical restorations and extractions ${ }^{3}$. Yellow and brown opacities are more porous than white ones, have worse prism organization and are easier for acids to attack ${ }^{5}$. In the most severe cases, the cusps and occlusal surfaces of the molars can disintegrate, favoring the appearance of a rapid progression of caries that does not form part of the childhood caries pattern ${ }^{6}$. Owing to the greater porosity of the enamel and its lower mechanical resistance ${ }^{7}, \mathrm{MIH}$ is considered a risk factor for dental caries in populations with low caries levels ${ }^{8-14}$.

In areas with high caries prevalence, MIH can remain undetected because the rapid advance of the caries eliminates any trace of the hypomineralization ${ }^{15}$. In areas where caries prevalence is moderate to low, however, the two conditions can coexist and can be differentiated as long as the MIH is not severe. If caries occurs, the mineralization disorder favors its rapid progress, causing major crown destruction and loss of the tooth. Additionally, the tooth sensitivity experienced by most of the children affected by MIH reduces oral hygiene and self-cleaning, increasing the risk of caries.

Most of the authors who have studied the association between $\mathrm{MIH}$ and dental caries $8,10,11,15-22$ have shown a relationship between increased DMFT and children with MIH compared to those without MIH. However, others such as Dietrich et al. ${ }^{23}$, Calderara et al. ${ }^{24}$ or Heitmüller et al. ${ }^{25}$ have not found a significant association between dental caries and MIH.

Appropriate exposure to fluoride and the introduction of programs to prevent and control etiological factors have made a decisive contribution to reducing dental caries, even though it continues to be a prevalent disease in the child population. The rise in MIH prevalence makes it necessary to study its possible relationship with dental 
caries. Since MIH seems to increase the risk of caries mainly in the permanent first molars, the aim of the present study was to discover whether there is a relationship between dental caries and $\mathrm{MIH}$, and its distribution in a sample of 8 to 9 year-old children.

\section{Materials and Methods}

Ethical considerations. The clinical study was authorized by the University of Valencia's human research ethics committee, under procedure number H1372162226937, in accordance with the Helsinki Declaration on Medical Research Involving Human Subjects. The procedures were explained clearly to all the parents/guardians and participants before their inclusion in the study and informed consent to oral examination and intraoral photography was obtained from all the parents/guardians of the children participating. The methods employed were applied in accordance with approved guidelines.

Study design. This cross-sectional study was part of a wider research project named INMA (the Spanish initials for infancy, childhood and the environment), which investigates the effects of environmental factors on the development and health of a cohort of children in the Valencia region of Spain whose mothers were recruited by consecutive sampling in early pregnancy and have been followed-up since their inclusion in 2003-2004 ${ }^{26,27}$. These children are examined at regular intervals and the 8-9 year-old appointment provided the opportunity to perform an oral examination.

Sample size calculation. A minimum sample size of 405 subjects was considered sufficient to estimate $\mathrm{MIH}$ prevalence with a $95 \%$ confidence level and a level of precision of $+/-4 \%$ in a population with an MIH level of around 20\%. The final sample comprised 414 children aged 8 and 9 years (born between 2004 and 2005) who attended the 8-9 year-old check-up, which included an oral examination.

Diagnostic criteria. Prior to the calibration session, the dentist who was to carry out the MIH examinations and a dental practitioner with experience in diagnosing and treating MIH conducted a standardization session. The diagnostic criteria were established as being those drawn up by the EAPD in $2003^{3}$, which match the current basis for studies of $\mathrm{MIH}^{4,28}$. They are as follows: white/yellow/brown demarcated opacities, considered a mild degree of MIH; or post-eruptive enamel breakdown associated with opacities, extensive caries with surrounding opacities or in low-risk surfaces, atypical restorations of a size and location unrelated to the caries pattern, teeth with crowns if $\mathrm{MIH}$ is found in other teeth, or extractions due to $\mathrm{MIH}$, which were considered a mild degree of MIH. The occlusal/incisal, labial and lingual/palatal surfaces of the permanent incisors and permanent first molars were assessed. Spots larger than $1 \mathrm{~mm}$ were classed as hypomineralized. MIH was diagnosed when a permanent first molar was affected by hypomineralization. Incisors were only diagnosed as MIH if a molar was affected. The degree of severity was decided by the most severe disorder in the child's mouth.

For caries diagnosis, the ICDAS II criteria were employed ${ }^{29,30}$. ICDAS grades 1 to 6 range from white spots to extensive caries. In grade 1 a white spot or visual change in the enamel is visible on drying the tooth; in grade 2 the white spot is visible on the moist tooth; in grade 3, localized enamel breakdown (with no visible dentin) is observed; in grade 4 there is dentinal shadow (with no visible dentin); in grade 5, a cavity with visible dentine, and in grade 6 , an extensive cavity with visible dentine affecting over half of a tooth surface.

The teeth examined were the index teeth for MIH (permanent first molars and permanent incisors). The DMFS index was calculated from the sum of the decayed (ICDAS codes 1 to 6), missing and filled surfaces of the teeth used to assess MIH.

Calibration of the examiners. The first calibration session for MIH was conducted with 46 clinical photographs which were used to assess all the degrees of hypomineralization (no MIH, mild MIH and severe MIH), as well as other disorders involved in a differential diagnosis, such as fluorosis, hypoplasia and amelogenesis imperfecta. The diagnostic agreement was $100 \%$. For dental caries, an online course in caries diagnosis using the ICDAS-II criteria ${ }^{31}$ was followed, which involved assessing images of different grades of dental caries.

A second calibration session was then carried out with 54 children who attended the pediatric dentistry unit in the stomatology department of the University of Valencia. The agreement measured by linear-weighted kappa was 0.83 for the MIH examiner and 0.91 for the dental caries examiner, which are considered good results on the Landis and Koch scale.

The data were collected by an MIH calibrated dentist and a different ICDAS II calibrated dentist and were recorded on dental charts to facilitate the data collection process and eliminate possible errors. A prior pilot study was conducted to clarify or correct any errors that arose.

Examination. The examinations were carried out at the pediatric dentistry unit in the stomatology department of the University of Valencia. The equipment consisted of two dental chairs with lighting, cotton swabs for removing excess plaque or saliva, flat mouth mirrors and sterilized standard no. 4/6 double-ended exploration probes.

The teeth were first examined when wet and were then dried with cotton swabs for MIH diagnosis and with the equipment's air jet, if necessary, for caries diagnosis. The data were collected on an examination record specifically prepared for this study, which had a section for personal details and a dental chart for recording the data on MIH and dental caries.

Questionnaire. At the time of the oral examination, the children completed a questionnaire with 18 multiple-choice items concerning their health knowledge, oral hygiene habits and diet (data no shown). Based on the responses to this questionnaire, three categorized variables were generated: cariogenic food intake, teeth brushing habits and fluoride intake. 


\begin{tabular}{|l|l|l|l|l|l|}
\hline Mean values & Total $(\mathbf{n}=\mathbf{4 1 4})$ & No MIH $(\mathbf{n}=\mathbf{3 1 4})$ & MIH $(\mathbf{n}=\mathbf{1 0 0})$ & Mild MIH $(\mathbf{n}=\mathbf{7 2})$ & Severe MIH $(\mathbf{n}=\mathbf{2 8})$ \\
\hline Component D & $1.11(0.95-1.28)$ & $1.08(0.90-1.27)$ & $1.22(0.84-1.60)$ & $1.03(0.61-1.44)$ & $1.71(0.83-2.59)$ \\
\hline Component F & $0.11(0.06-0.16)$ & $0.09(0.04-0.14)$ & $0.18(0.06-0.30)$ & $0.06(0.00-0.12)$ & $0.50(0.10-0.90)$ \\
\hline DMFS index & $1.23(1.05-1.41)$ & $1.18(0.98-1.38)$ & $1.40(0.99-1.81)$ & $1.08(0.67-1.50)$ & $2.21^{1,2}(1.23-3.20)$ \\
\hline
\end{tabular}

Table 1. DMFS distribution for children with and without MIH. Mean values with $95 \%$ CI in parentheses. For both groups, M was a constant equal to zero. ${ }^{1}$ Significant difference compared to no MIH according to post-hoc ANOVA ( $\mathrm{p}<0.05)$. ${ }^{2}$ Significant difference compared to mild MIH according to post-hoc ANOVA $(\mathrm{p}<0.05)$.

Cariogenic food intake was considered high if the child consumed sugary drinks or foods during and/or between main meals every day of the week, moderate if they were consumed between 4 and 6 days a week, and low if consumed a maximum of 3 days a week. Oral hygiene was considered correct when the child brushed his/ her teeth at least once a day, poor if less than once a day and absent if the teeth were not brushed. Fluoride intake was considered good if the teeth were brushed with fluoride toothpaste more than once a day and a fluoride mouthwash was used weekly or every 2 weeks, moderate if the teeth were brushed with fluoride toothpaste only once a day and fluoride mouthwash was used occasionally, poor when brushing with fluoride toothpaste was performed less than once a day and no fluoride mouthwash was used, and absent when the teeth were brushed without fluoride toothpaste and no fluoride mouthwash was used.

Statistical analysis. The completed examination records were entered into an Access ${ }^{\circledR}$ data base (Access 2003; Microsoft Corporation, Redmont, WA, USA) and transferred to an Excel ${ }^{\circledR}$ spreadsheet (Excel 2003; Microsoft Corporation, Redmont, WA, USA) for treatment by the SPSS Statistics $22.0^{\circledR}$ program (IBM SPSS, Chicago, IL, USA).

The study variables were: MIH diagnosis, MIH level (mild or severe), DMFS index and its components, caries prevalence (DMFS $>0$ ), tooth-surface caries ratio (the number of decayed or filled surfaces divided by the total number of exposed surfaces), cariogenic food intake (classed as low, moderate or high), oral hygiene habits (classed as correct, poor or absent) and fluoride intake (good, moderate, poor or absent).

Descriptive statistics were calculated, with means and confidence intervals for the quantitative variables and percentages and confidence intervals for the qualitative variables. The normality of the distributions was tested with Kolmogorov-Smirnov's test. Student's t-test or ANOVA were used to determine significant differences between means and a chi-squared test was used to detect differences in proportions. Taking the DMFS index as the dependent variable and cariogenic food intake, teeth brushing habits and fluoride intake as the independent variables, mild MIH and severe MIH were analyzed with a linear regression model. The level of significance was set at $\mathrm{p}<0.05$.

\section{Results}

A total of 414 children (212 boys and 202 girls) with an average age of 9.16 years (95\% CI 9.13-9.18) were examined. In total, $24.2 \%$ (100 children) had MIH. Of these, $72 \%$ had a mild form and $28 \%$ a severe form. No statistically significant differences by gender were encountered in a Chi squared test $(\mathrm{p}=0.521)$. Within the group of children diagnosed as having MIH, the mean number of teeth affected were 2.7 permanent first molars and 1.3 permanent incisors.

The caries prevalence (DMFS >0) in the sample was $45.9 \%$. In the children with MIH it was $48 \%$ and in those without $\mathrm{MIH} 45.5 \%$, with no statistically significant differences $\left(\mathrm{Chi}^{2} \mathrm{p}=0.627\right)$. On comparing the children with $\mathrm{MIH}$ according to the degree of severity, however, significant differences in caries prevalence $\left(\mathrm{Chi}^{2} \mathrm{p}=0.0251\right)$ were encountered between those with mild MIH (43.1\%) and with severe MIH (60.7\%).

The DMFS index score for the total sample was 1.23. It was 1.40 for the children with MIH and 1.18 for those without MIH (Table 1). No statistically significant differences in DMFS score were encountered between these two groups $(\mathrm{p}=0.30)$.

The DMFS index score was 1.08 for the children with mild MIH and 2.21 for those with severe MIH. An ANOVA showed differences in DMFS $(\mathrm{p}=0.012)$ (Table 1$)$. The post hoc ANOVA indicated that the differences in DMFS were mostly between the children with no MIH and those with severe MIH $(\mathrm{p}=0.013)$ and between those with mild MIH and severe MIH $(\mathrm{p}=0.016)$. A linear tendency was observed, as the mean DMFS values increased in line with the degree of severity.

The tooth-surface caries ratio of the children without $\mathrm{MIH}$ was 0.04 (95\% CI 0.03-0.05). For those with mild MIH it was 0.04 (95\% CI 0.02-0.06) overall, but 0.02 (95\% CI 0.01-0.03) in surfaces without hypomineralization and 0.11 (95\% CI 0.06-0.15) where hypomineralization was present and the difference was statistically significant $(\mathrm{p}=0.001)$. For children with severe $\mathrm{MIH}$ the ratio was 0.08 (95\% CI $0.04-0.12)$, with 0.02 (95\% CI 0.01-0.04) for surfaces without MIH, 0.12 (95\% CI 0.02-0.20) for surfaces with mild hypomineralization and 0.40 (95\% CI $0.22-0.59)$ for surfaces with severe hypomineralization.

In the children with mild $\mathrm{MIH}$, the tooth-surface caries ratio was greater for hypomineralized surfaces than for those with no hypomineralization, and the difference was statistically significant $(p=0.001)$. In the children with severe $\mathrm{MIH}$, statistically significant differences in ratio were found between surfaces with mild hypomineralization and no hypomineralization $(\mathrm{p}=0.038)$, and between surfaces with mild and severe hypomineralization $(p=0.01)$. There were no statistically significant differences in ratio between the three groups for surfaces without hypomineralization $(\mathrm{p}=0.976)$, or between children with mild MIH and severe MIH for surfaces affected by mild hypomineralization $(\mathrm{p}=0.871)$. The ratios are shown in Fig. 1. 


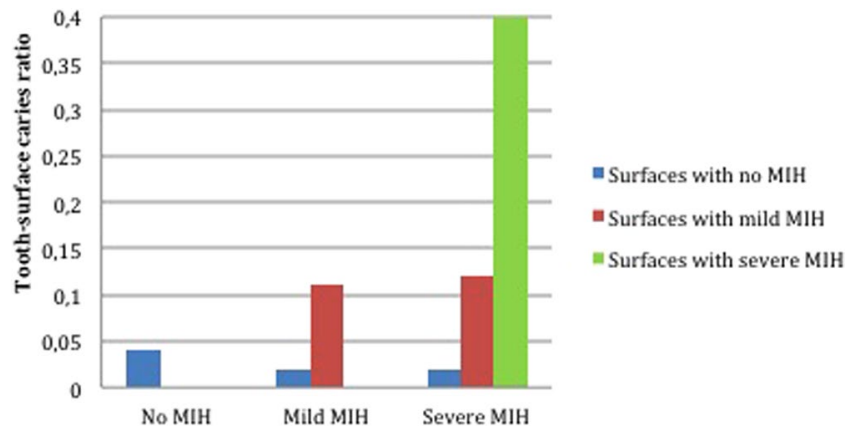

Figure 1. Tooth-surface caries ratio by hypomineralization level for each MIH group.

\begin{tabular}{|c|c|c|c|c|c|c|}
\hline & & $\mathbf{n}$ & Frequency & $\begin{array}{l}\text { Mean } \\
\text { DMFS score }\end{array}$ & $95 \%$ CI & $\begin{array}{l}\text { ANOVA } \\
\text { p-value }\end{array}$ \\
\hline \multirow{3}{*}{$\begin{array}{l}\text { Cariogenic food } \\
\text { intake }\end{array}$} & Low & 229 & $55.3 \%$ & 1.03 & $0.82-1.24$ & \multirow{3}{*}{$0.019^{*}$} \\
\hline & Moderate & 147 & $35.5 \%$ & 1.38 & $1.05-1.72$ & \\
\hline & High & 38 & $9.2 \%$ & 1.84 & $1.20-2.47$ & \\
\hline \multirow{3}{*}{$\begin{array}{l}\text { Oral hygiene } \\
\text { habits }\end{array}$} & Correct & 82 & $19.8 \%$ & 1.15 & $0.74-1.56$ & \multirow{3}{*}{0.108} \\
\hline & Poor & 223 & $53.9 \%$ & 1.10 & $0.88-1.33$ & \\
\hline & Absent & 109 & $26.3 \%$ & 1.55 & $1.16-1.94$ & \\
\hline \multirow{4}{*}{ Fluoride intake } & Good & 67 & $16.2 \%$ & 1.22 & $0.78-1.66$ & \multirow{4}{*}{0.700} \\
\hline & Moderate & 173 & $41.8 \%$ & 1.32 & $1.03-1.61$ & \\
\hline & Poor & 147 & $35.5 \%$ & 1.19 & $0.91-1.48$ & \\
\hline & Absent & 27 & $6.5 \%$ & 0.88 & $0.25-1.52$ & \\
\hline
\end{tabular}

Table 2. Frequency of variables and mean DMFS score by variable. *Significant difference $(\mathrm{p}<0.05)$.

\begin{tabular}{|l|c|l|}
\hline $\begin{array}{l}\text { Variables related to } \\
\text { DMFS }\end{array}$ & $\begin{array}{l}\boldsymbol{\beta} \text { coefficients } \\
\text { (unstandardized) }\end{array}$ & P value \\
\hline Constant & 0.806 & 0.001 \\
\hline Cariogenic food intake & 0.073 & $0.02^{*}$ \\
\hline $\begin{array}{l}\text { Unfavorable tooth } \\
\text { brushing habits }\end{array}$ & 0.206 & 0.122 \\
\hline Fluoride intake & -0.089 & 0.411 \\
\hline Presence of mild MIH & -0.131 & 0.578 \\
\hline Presence of severe MIH & 1.095 & $0.002^{*}$ \\
\hline
\end{tabular}

Table 3. Linear regression model fitting DMFS to the independent variables. ${ }^{*} \mathrm{p}<0.05$.

The distribution of the cariogenic food intake, oral hygiene habits and fluoride intake variables in relation to the DMFS index is shown in Table 2. The only significant differences in DMFS were between low and high intake of cariogenic foods (post-hoc $\mathrm{p}=0.012$ ). Moreover, a linear trend was observed in the mean DMFS score, which rose as the cariogenic food intake increased $(\mathrm{p}=0.012)$.

A linear regression model was constructed with the DMFS score as the dependent variable and cariogenic foods, tooth brushing, fluoride intake, mild $\mathrm{MIH}$ and severe $\mathrm{MIH}$ as the independent variables. The model obtained $\mathrm{R}^{2}=0.044$ and $\mathrm{p}=0.002$. Severe MIH $(\mathrm{p}=0.002)$ and cariogenic food intake $(\mathrm{p}=0.020)$ were shown to be significant and independent variables in this model (Table 3 ).

The final model constructed with the two significant variables met the linearity criterion (ANOVA $p=0.000)$. The residuals fulfilled the conditions of independence (Durbin-Watson $=1,94$ ), homoscedasticity (absence of association in the dispersion plot between predicted values and residuals) and normality (Kolmogorv-Smirnov's test $\mathrm{p}=0.200$ ). Finally there was no co-linearity between the two significant variables (Pearson correlation $=-0.040$ ).

\section{Discussion}

MIH prevalence varies between $2.9 \%$ and $44 \%$ in different countries ${ }^{4}$. In Spain it ranges between $12.4 \%$ and $21.8 \%^{8,32,33}$, with $24.2 \%$ observed in the present study. MIH is most often encountered in a mild form ${ }^{8,10,12,15,24,33-37}$, which agrees with the results of the present study, where $72 \%$ of the MIH cases were mild and $28 \%$ severe.

Most authors have concluded that there is a relationship between hypomineralized teeth and dental caries $^{8,10,11,15-22}$. However, others have stated that hypomineralization does not predispose towards caries in 
hypomineralized teeth ${ }^{23-25}$. In the present study, no statistically significant differences in caries prevalence were found between children with MIH (irrespective of level) and without MIH (48\% and 45.5\% respectively). However, on distinguishing between different levels of $\mathrm{MIH}$, the severe $\mathrm{MIH}$ cases had significantly higher caries prevalence than those with mild $\mathrm{MIH}(60.7 \%$ and $43.1 \%$ respectively, $\mathrm{p}=0.0251)$, which would indicate that more severe MIH entails a higher susceptibility to caries.

In the present study, as in Heitmuller et al..$^{25}$, no statistically significant differences in DMFS between children with no MIH and those with mild MIH were observed. Few previous studies have distinguished between different levels of MIH when assessing differences in caries scores. In the present case, the caries scores were significantly higher in children with severe MIH compared to those with mild MIH or no MIH. Also, a linear tendency was found in mean DMFS scores, which rose as the severity of the hypomineralization increased.

It has been said that one of the main risks of observational bias when studying the relationship between $\mathrm{MIH}$ and caries is that the examiner who records the presence or absence of caries is necessarily also seeing the presence or absence of $\mathrm{MIH}$, and vice versa, hence the recommendation that $\mathrm{MIH}$ and caries be assessed by two different examiners ${ }^{38}$. In this study, the MIH and caries evaluations, the latter using the ICDAS criteria, were conducted independently by two separate observers after calibration in the respective methods.

Several studies have shown that children with MIH need more dental treatment (whether urgent, non-urgent or preventive) than those without $\mathrm{MIH}^{8,11,15,16,18,39}$. MIH has an impact on increased caries prevalence and on restoration work in permanent first molars ${ }^{16,18}$. The higher scores for DMFS and its F component obtained in the present study confirm that children with severe MIH need more fillings.

The tooth-surface caries ratio rises as the severity of hypomineralization increases ${ }^{5}$. This could be because opacities in the cream to brown color range are more porous ${ }^{5}$ and more susceptible to PEB, and PEB, in turn, exacerbates the caries and increases its severity. Kosma et al. ${ }^{22}$ observed that the more severe the MIH the greater the caries, which agrees with Pitiphat et al. ${ }^{20}$, who found that caries lesions are 10 times more frequent in teeth with PEB (severe MIH) than in teeth that only have opacities (mild MIH). Elfrink et al..$^{40}$ observed that the mean density of the hydroxyapatite in opacities in the yellow to brown color range is $20 \%$ to $22 \%$ lower than in sound enamel, while the difference is almost nonexistent in white opacities. The results of the present study have also shown that the caries is far greater in surfaces with severe MIH than in surfaces with mild MIH or no MIH.

The variability in the results of studies that have investigated the relationship between MIH and dental caries suggests the need for a standard protocol that would allow comparative analysis and strengthen the evidence for the conclusions. The present study followed the MIH diagnostic criteria established by EAPD ${ }^{3}$, which agree with the current guidelines proposed at the 12th EAPD Congress held in Sopot (Poland) in 2014 and published by Elfrink et al. ${ }^{4}$ and Ghanim et al. ${ }^{28}$.

This study provides detailed information on the caries status of teeth with $\mathrm{MIH}$, distinguishing between caries in surfaces with mild hypomineralization or with severe hypomineralization in order to measure which level of the disease has a greater association with MIH. Caries was measured in the occlusal, labial and palatal/lingual surfaces of molars and incisors, the teeth that are liable to MIH. Other authors have also examined for caries in interproximal surfaces ${ }^{8,10,35,41}$ but these cannot be examined for $\mathrm{MIH}$, which could lead to underestimating the relationship between MIH and caries. Also, in the present authors' opinion, studies that include all the teeth ${ }^{8,17,19-21,25,42-46}$ can skew the results because of the greater number of teeth and because they cannot be compared with the index teeth for MIH.

As regards caries diagnosis, the criteria used in the different studies have also differed: most have followed the WHO criteria ${ }^{8,15-17,19-22,24,39,42}$ and very few have used ICDAS ${ }^{18}$ or the Universal Visual Scoring System ${ }^{25}$. The lack of agreement between the ICDAS ${ }^{29,30}$ and $\mathrm{WHO}^{47}$ diagnostic criteria could make it difficult to achieve an adequate assessment of the epidemiological trend in dental caries, which is why the EAPD prescribed the use of ICDAS II for caries prevalence studies ${ }^{48}$. The ICDAS II system enables initial stages of caries to be coded, unlike the WHO system, which only scores active caries lesions (ICDAS II codes 4, 5 and 6) and therefore underestimates the level of caries.

Some authors do not include filled teeth in their DMF scores if they believe them to be associated with atypical caries due to $\mathrm{MIH}^{25}$, and therefore obtain lower DMF values, but most atypical restorations in teeth affected by MIH have involved a history of caries even if it cannot be established with certainty at the time of examination. Consequently these authors could be underestimating the DMF, while those who include all fillings in the DMF could be overestimating it. In the present study, following the EAPD criteria ${ }^{3}$, extensive or atypical restorations were included in the MIH diagnosis if they had opacities around the edges or on another surface of the tooth or if $\mathrm{MIH}$ criteria applied to another molar.

Diet and oral hygiene play an important role in the etiological factors of caries and the present study observed a rise in mean DMFS as the intake of cariogenic foods increased. The multifactorial analysis found that cariogenic food intake and the presence of severe MIH were significantly related to higher DMFS scores, but that mild MIH showed no association with dental caries.

Preventive measures against dental caries involve improving oral hygiene and changing the child's dietary habits. Applying fluoride as a varnish or in trays, and in toothpaste or rinses, is also effective. Nevertheless, it is also important to treat active lesions, whether by remineralizing an incipient or chronic lesion or by filling a cavitated lesion. It is very important to monitor teeth with signs of MIH to avoid their premature loss from dental caries, examining primary molars for hypomineralization and, if they are affected, monitoring the development of the permanent first molars ${ }^{49}$. These children should also be included in a high caries risk follow-up protocol.

The present study examined the association between MIH and dental caries and found an association between dental caries and the presence of surfaces affected by severe $\mathrm{MIH}$, which should be considered a risk factor within the multifactorial etiology of caries. 


\section{References}

1. Vargas-Ferreira, F., Zeng, J., Thomson, W. M., Peres, M. A. \& Demarco, F. F. Association between developmental defects of enamel and dental caries in schoolchildren. J Dent. 42, 540-546 (2014).

2. Correa-Faria, P. et al. Association between developmental defects of enamel and early childhood caries: a cross-sectional study. Int J Paediatr Dent. 25, 103-109 (2015).

3. Weerheijm, K. L. et al. Judgement criteria for molar incisor hypomineralisation (MIH) in epidemiologic studies: a summary of the European meeting on MIH held in Athens, 2003. Eur J Paediatr Dent. 4, 110-113 (2003).

4. Elfrink, M. E., Ghanim, A., Manton, D. J. \& Weerheijm, K. L. Standardised studies on Molar Incisor Hypomineralisation (MIH) and Hypomineralised Second Primary Molars (HSPM): a need. Eur Arch Paediatr Dent. 16, 247-255 (2015).

5. Jalevik, B. \& Noren, J. G. Enamel hypomineralization of permanent first molars: a morphological study and survey of possible aetiological factors. Int J Paediatr Dent. 10, 278-289 (2000).

6. Weerheijm, K. L. Molar incisor hypomineralisation (MIH). Eur J Paediatr Dent. 4, 114-120 (2003).

7. Mahoney, E., Ismail, F. S., Kilpatrick, N. \& Swain, M. Mechanical properties across hypomineralized/hypoplastic enamel of first permanent molar teeth. Eur J Oral Sci. 112, 497-502 (2004).

8. Garcia-Margarit, M., Catala-Pizarro, M., Montiel-Company, J. M. \& Almerich-Silla, J. M. Epidemiologic study of molar-incisor hypomineralization in 8-year-old Spanish children. Int J Paediatr Dent. 24, 14-22 (2014).

9. Weerheijm, K. L., Jalevik, B. \& Alaluusua, S. Molar-incisor hypomineralisation. Caries Res. 35, 390-391 (2001).

10. Leppaniemi, A., Lukinmaa, P. L. \& Alaluusua, S. Nonfluoride hypomineralizations in the permanent first molars and their impact on the treatment need. Caries Res. 35, 36-40 (2001).

11. Jalevik, B. \& Klingberg, G. A. Dental treatment, dental fear and behaviour management problems in children with severe enamel hypomineralization of their permanent first molars. Int J Paediatr Dent. 12, 24-32 (2002).

12. Jalevik, B., Klingberg, G., Barregard, L. \& Noren, J. G. The prevalence of demarcated opacities in permanent first molars in a group of Swedish children. Acta Odontol Scand. 59, 255-260 (2001).

13. Jalevik, B. \& Moller, M. Evaluation of spontaneous space closure and development of permanent dentition after extraction of hypomineralized permanent first molars. Int J Paediatr Dent. 17, 328-35 (2007).

14. Elfrink, M. E. et al. Factors increasing the caries risk of second primary molars in 5-year-old Dutch children. Int J Paediatr Dent. 20, 151-157 (2010).

15. da Costa-Silva, C. M. et al. Molar incisor hypomineralization: prevalence, severity and clinical consequences in Brazilian children. Int J Paediatr Dent. 20, 426-434 (2010).

16. Muratbegovic, A., Markovic, N. \& Ganibegovic-Selimovic, M. Molar incisor hypomineralisation in Bosnia and Herzegovina: aetiology and clinical consequences in medium caries activity population. Eur Arch Paediatr Dent. 8, 189-194 (2007).

17. Cho, S. Y., Ki, Y. \& Chu, V. Molar incisor hypomineralization in Hong Kong Chinese children. Int J Paediatr Dent. 18, 348-352 (2008).

18. Ghanim, A. M., Manton, D. J., Morgan, M. V., Marino, R. J. \& Bailey, D. L. Trends of oral health care and dental treatment needs in relation to molar incisor hypomineralisation defects: a study amongst a group of Iraqi schoolchildren. Eur Arch Paediatr Dent. 13, 171-178 (2012).

19. Jeremias, F. et al. Dental caries experience and Molar-Incisor Hypomineralization. Acta Odontol Scand. 71, 870-876 (2013).

20. Pitiphat, W., Savisit, R., Chansamak, N. \& Subarnbhesaj, A. Molar incisor hypomineralization and dental caries in six- to seven-yearold Thai children. Pediatr Dent. 36, 478-482 (2014).

21. Petrou, M. A. et al. Severity of MIH findings at tooth surface level among German school children. Eur Arch Paediatr Dent. 16, 271-276 (2015)

22. Kosma, I., Kevrekidou, A., Boka, V., Arapostathis, K. \& Kotsanos, N. Molar incisor hypomineralisation (MIH): correlation with dental caries and dental fear. Eur Arch Paediatr Dent. 17, 123-129 (2016).

23. Dietrich, G., Sperling, S. \& Hetzer, G. Molar incisor hypomineralisation in a group of children and adolescents living in Dresden (Germany). Eur J Paediatr Dent. 4, 133-137 (2003).

24. Calderara, P. C. et al. The prevalence of Molar Incisor Hypomineralisation (MIH) in a group of Italian school children. Eur J Paediatr Dent. 6, 79-83 (2005).

25. Heitmuller, D. et al. Is there a positive relationship between molar incisor hypomineralisations and the presence of dental caries? Int J Paediatr Dent. 23, 116-124 (2013).

26. Guxens, M. et al. Cohort Profile: the INMA-INfancia y Medio Ambiente-(Environment and Childhood) Project. Int J Epidemiol. 41, 930-940 (2012).

27. Ribas-Fito, N. et al. Child health and the environment: the INMA Spanish Study. Paediatr Perinat Epidemiol. 20, 403-410 (2006).

28. Ghanim, A., Elfrink, M., Weerheijm, K., Marino, R. \& Manton, D. A practical method for use in epidemiological studies on enamel hypomineralisation. Eur Arch Paediatr Dent. 16, 235-246 (2015).

29. International Caries Detection and Assessment System (ICDAS) Coordinating Committee. Criteria Manual: International Caries Detection and Assessment System (ICDAS II). Available at: http://www.icdas.org/downloads. Accessed October 2013, Workshop held in Baltimore, Maryland, March 12th-14th 2005. Revised in December 2008 in Bogota, Colombia and in July 2009 in Budapest, Hungary.

30. Ismail, A. I. et al. The International Caries Detection and Assessment System (ICDAS): an integrated system for measuring dental caries. Community Dent Oral Epidemiol. 35, 170-178 (2007).

31. ICDAS Foundation E-Learning page. A 90-minute e-learning program developed to support training in the use of ICDAS. Available at: https://www.icdas.org/icdas-e-learning-course. AccessedOctober, 2013.

32. Comes-Martínez, Á., Puente-Ruiz, C. \& Rodríguez-Salvanés, F. Prevalencia de Hipomineralización en primeros molares permanentes (MIH) en población infantil del Área 2 de Madrid. RCOE. 12, 129-134 (2007).

33. Martinez-Gomez, T. P., Guinot-Jimeno, F., Bellet-Dalmau, L. J. \& Giner-Tarrida, L. Prevalence of molar-incisor hypomineralisation observed using transillumination in a group of children from Barcelona (Spain). Int J Paediatr Dent. 22, 100-109 (2012).

34. Kusku, O. O., Caglar, E. \& Sandalli, N. The prevalence and aetiology of molar-incisor hypomineralisation in a group of children in Istanbul. Eur J Paediatr Dent. 9, 139-144 (2008).

35. Koch, G. et al. Epidemiologic study of idiopathic enamel hypomineralization in permanent teeth of Swedish children. Community Dent Oral Epidemiol. 15, 279-285 (1987).

36. Lygidakis, N. A., Dimou, G. \& Briseniou, E. Molar-incisor-hypomineralisation (MIH). Retrospective clinical study in Greek children. I. Prevalence and defect characteristics. Eur Arch Paediatr Dent. 9, 200-206 (2008).

37. Mittal, N. \& Sharma, B. B. Hypomineralised second primary molars: prevalence, defect characteristics and possible association with Molar Incisor Hypomineralisation in Indian children. Eur Arch Paediatr Dent. 16, 441-7 (2015).

38. Americano, G. C., Jacobsen, P. E., Soviero, V. M. \& Haubek, D. A systematic review on the association between molar incisor hypomineralization and dental caries. Int J Paediatr Dent. 27, 11-21 (2017).

39. Kotsanos, N., Kaklamanos, E. G. \& Arapostathis, K. Treatment management of first permanent molars in children with MolarIncisor Hypomineralisation. Eur J Paediatr Dent. 6, 179-184 (2005).

40. Elfrink, M. E., ten Cate, J. M., van Ruijven, L. J. \& Veerkamp, J. S. Mineral content in teeth with deciduous molar hypomineralisation (DMH). J Dent. 41, 974-978 (2013). 
41. van Amerongen, W. E. \& Kreulen, C. M. Cheese molars: a pilot study of the etiology of hypocalcifications in first permanent molars. ASDC J Dent Child. 62, 266-269 (1995).

42. Preusser, S. E., Ferring, V., Wleklinski, C. \& Wetzel, W. E. Prevalence and severity of molar incisor hypomineralization in a region of Germany-a brief communication. J Public Health Dent. 67, 148-150 (2007).

43. Jalevik, B. \& Klingberg, G. Treatment outcomes and dental anxiety in 18-year-olds with MIH, comparisons with healthy controls - a longitudinal study. Int J Paediatr Dent. 22, 85-91 (2012).

44. Mahoney, E. K. \& Morrison, D. G. Further examination of the prevalence of MIH in the Wellington region. N Z Dent J. 107, 79-84 (2011).

45. Mahoney, E. K. \& Morrison, D. G. The prevalence of Molar-Incisor Hypomineralisation (MIH) in Wainuiomata children. NZ Dent J. 105, 121-127 (2009).

46. Groselj, M. \& Jan, J. Molar incisor hypomineralisation and dental caries among children in Slovenia. Eur J Paediatr Dent. 14, 241-245 (2013).

47. World Health Organization. Oral health surveys: basic methods (ed,World Health Organization). (Geneva, 1997).

48. Kuhnisch, J. et al. Best clinical practice guidance for management of early caries lesions in children and young adults: an EAPD policy document. Eur Arch Paediatr Dent. 17, 3-12 (2016).

49. Negre-Barber, A., Montiel-Company, J. M., Boronat-Catala, M., Catala-Pizarro, M. \& Almerich-Silla, J. M. Hypomineralized Second Primary Molars as Predictor of Molar Incisor Hypomineralization. Sci Rep. 25, 6-31929 (2016).

\section{Acknowledgements}

The manuscript was translated into English by Mary Georgina Hardinge. This study was conducted as part of project PI12/02570, funded by the 2008-2011 Spanish national R\&D\&I Plan and the ISCIII (Instituto de Salud Carlos III) Subdirectorate General for Research Assessment and Promotion with cofunding from the European Regional Development Fund.

\section{Author Contributions}

A. Negre contributed to planning the study, data collection, statistical analysis and critical revision of the manuscript. J.M. Montiel contributed to the design, and interpretation of the statistical analysis and the critical revisión of the manuscript. M. Catalá and J.M. Almerich contributed to the design and planning and the critical revision of the manuscript. All the authors approved the final version and agreed on all aspects of the work.

\section{Additional Information}

Competing Interests: The authors declare that they have no competing interests.

Publisher's note: Springer Nature remains neutral with regard to jurisdictional claims in published maps and institutional affiliations.

(1) Open Access This article is licensed under a Creative Commons Attribution 4.0 International (c) License, which permits use, sharing, adaptation, distribution and reproduction in any medium or format, as long as you give appropriate credit to the original author(s) and the source, provide a link to the Creative Commons license, and indicate if changes were made. The images or other third party material in this article are included in the article's Creative Commons license, unless indicated otherwise in a credit line to the material. If material is not included in the article's Creative Commons license and your intended use is not permitted by statutory regulation or exceeds the permitted use, you will need to obtain permission directly from the copyright holder. To view a copy of this license, visit http://creativecommons.org/licenses/by/4.0/.

(C) The Author(s) 2018 